\title{
EARLY TREATMENT OF TRAUMATIC PARAPLEGIA
}

\author{
By Friedrich W. MeINeCKe, M.D. \\ Berufsgenossenschaftliche Krankenanstalten 'Bergmannsheil' \\ Surgical Department, Bochum, Germany
}

INTRODUCTION AND CLINICAL MATERIAL

SINCE 1945, we have treated in our hospital approximately 500 freshly injured paraplegic patients. Apart from these, a great number of paraplegics were admitted for examination or for treatment of complications which had developed since discharge. The following article will outline our methods of treatment in the early stage of paraplegia.

As our hospital is located in the centre of the Ruhr area, the prevailing number of admissions consists of miners injured by falling coal or stone. Among these, injuries at the thoraco-lumbar junction (Ioth dorsal vertebra-2nd lumbar vertebra) are most common. Injuries of the cervical region of the spinal cord are considerably less frequent and occur mainly in traffic, sport and domestic accidents.

\section{IMMEDIATE MEASURES FOLLOWING ADMISSION TO HOSPITAL}

Admission usually takes place a few hours after the accident, as long underground ways of transport are necessary.

The first and most important measure taken is treatment of shock, after which we proceed to diagnosis. Clinical assessment of bone injuries and neurological findings determine the procedures necessary. Secondary injuries are carefully looked for. Only if the patient is in an extremely serious condition do we dispense with X-ray examination, which otherwise is of utmost importance for the diagnosis of injuries of the skeletal system.

Treatment of the Fractured Spine. A few fundamental remarks may be relevant here:

I. The extent of damage to the spinal cord cannot be seen on the roentgenogram (Guttmann, 1953, 1954; Meinecke, 1963; Tönnis, 1963). There are considerable dislocations without neurological disturbances (figs. I and 2). On the other hand, there are extensive spinal cord injuries without evidence of changes of the bone structure revealed in the X-ray (fig. 3). On this point, there is complete agreement in the literature.

2. From the above, it necessarily follows that any method of reduction must be determined by the consideration of preventing any further damage to the spinal cord. The spinal cord evidently has a remarkable ability to escape damage than would seem possible (fig. 4). Again and again necropsy findings demonstrate that even in cases of fracture-luxations of high degree, complete severance of the spinal cord is a rarity. This knowledge should be decisive in determining kind and duration of the method of reduction.

3. Blood circulation of the spinal cord is dependent upon a few blood vessels only. Blood supply is smaller in border areas (Dio) as well as in the central sections around the spinal canal (Zülch, I954; Tönnis, I963). 


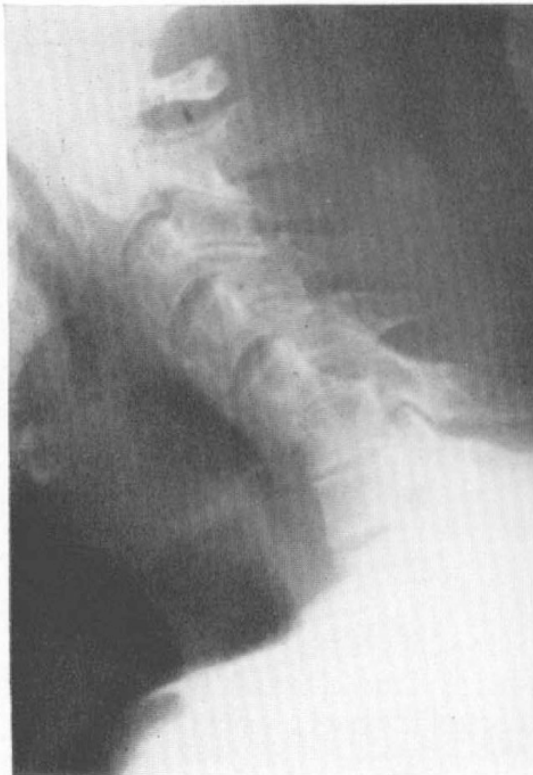

FIG. I

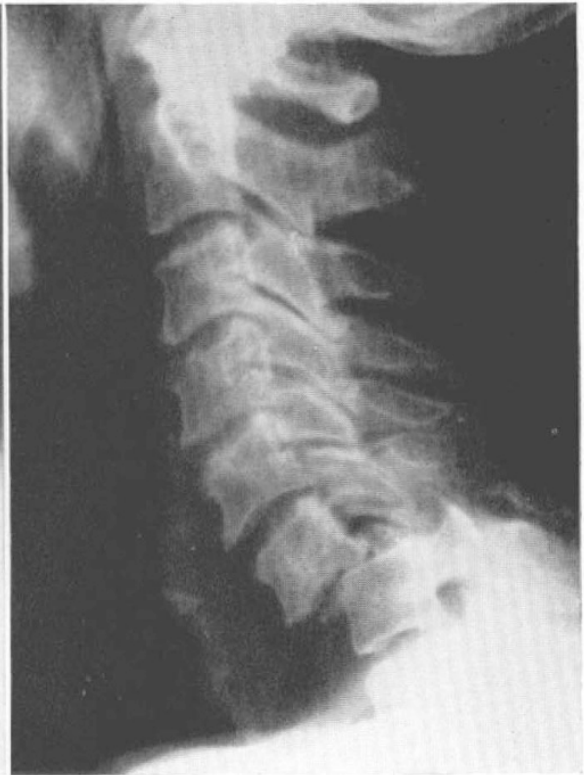

FIG. 2

FIG. I. H. O., dislocation of 6th cervical vertebra without neurological disturbances. First diagnosis I5 months after accident.

FIG. 2. G. E., dislocation of 7 th cervical vertebra, fracture of spinous process of 6 th cervical vertebra; no paralysis, slightly unpleasant sensations in finger-tips.

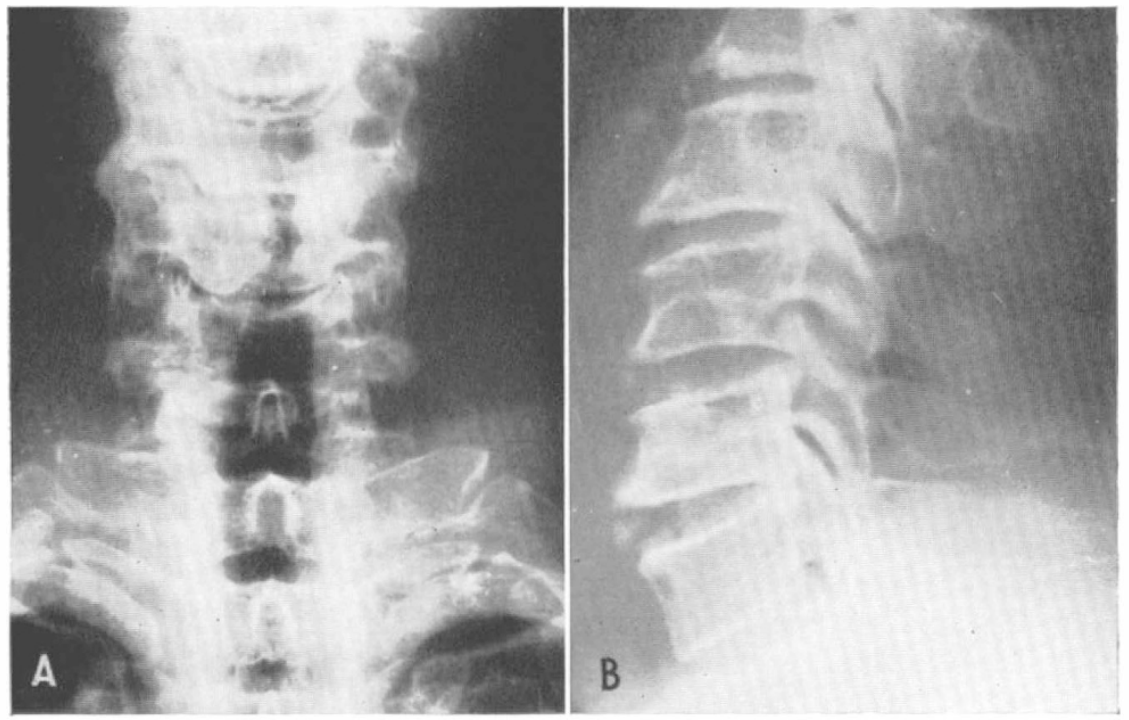

Figs. $3 a$ and $3 b$

A. E., tetraplegia, no significant pathological X-ray findings; roentgenogram on day of accident. 
Here ischaemia of a lesser sort can already effect definite damage of neural tissue. However, in cases where an improvement of paralysis does not occur, good alignment of the spinal longitudinal axis does improve the prospects for future weight-bearing of the spine. Attempts must naturally be made to take as much pressure off the spinal cord as possible, provided this can be managed without causing any further damage. For these reasons, we oppose immediate operative

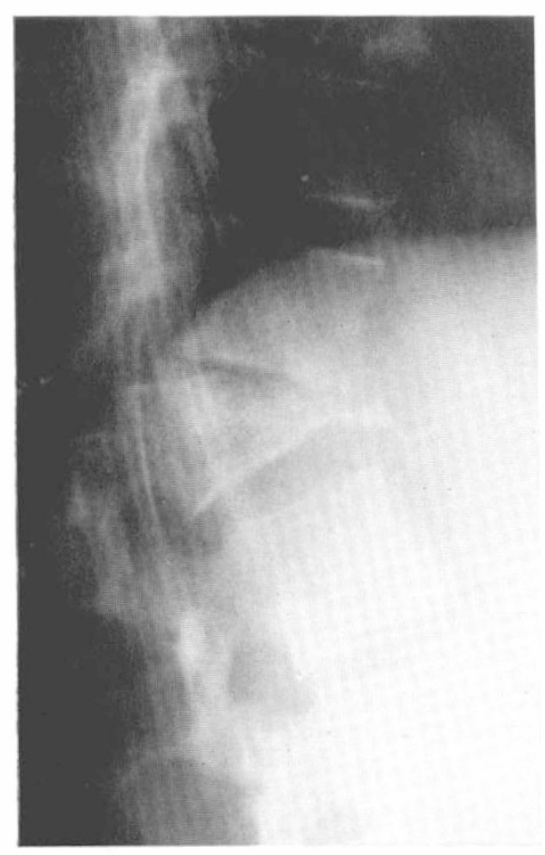

FIG. 4

G. W., fracture of Ist lumbar vertebra with initial complete paraplegia; recovery of function in leg muscles, patient walks without calipers. treatment as long as we are not dealing with an open injury. In peace-time, this is an exception. Operative procedures change the closed spinal injury into an open one. There is danger of infection of the soft tissues as well as of the spinal cord and its membranes. Proceeding to the site of the cord injury is necessarily associated with causing damage to those tissues which are responsible for the stability of the spinal column (muscles, ligaments, bones). It also results in loss of numerous blood vessels, so that blood flow to the critical areas, which is affected anyway, will be cut down even further.

We are opposed to immediate laminectomy, particularly as there exists no evidence that this method of treatment clearly leads to recovery of paralysis more frequently than conservative treatment. The only exception is when paralysis clearly develops after the time of accident or when neurological examination, which is repeated at intervals of a few hours, shows a progression of paralysis. In these cases, it is most likely that it is mechanical pressure exclusively which is producing progressive paralysis by oedema or bleeding of the spinal cord and that these have developed after a primary tissue dam-

age. Evidence of increasing pressure justifies the risk connected with operative relief of pressure.

By far the largest number of our patients were submitted to non-operative reduction and fixation-a procedure employed also in numerous patients with fractures of the spine without paralysis. This method corresponds to the principles set up by Böhler (I95I) (figs. $5 a$ and $b$ ). Deep anaesthesia facilitates this treatment considerably, as a complete relaxation of the muscular apparatus is thus achieved. The cervical spine reduction is effected manually. Dislocations of the dorsal and lumbar spine are treated by longitudinal traction while the patient is placed in prone position. If there is clear evidence of successful reduction, the fracture is set by hyperextension. The results of the individual phases of treatment are controlled by radiography (Bürkle de la Camp, I959; Meinecke, I960).

This procedure has sometimes been condemned as being too dangerous, as the considerable effects of traction could damage the blood vessels, thereby causing further damage to the spinal cord. It cannot be denied that there is the possibility 

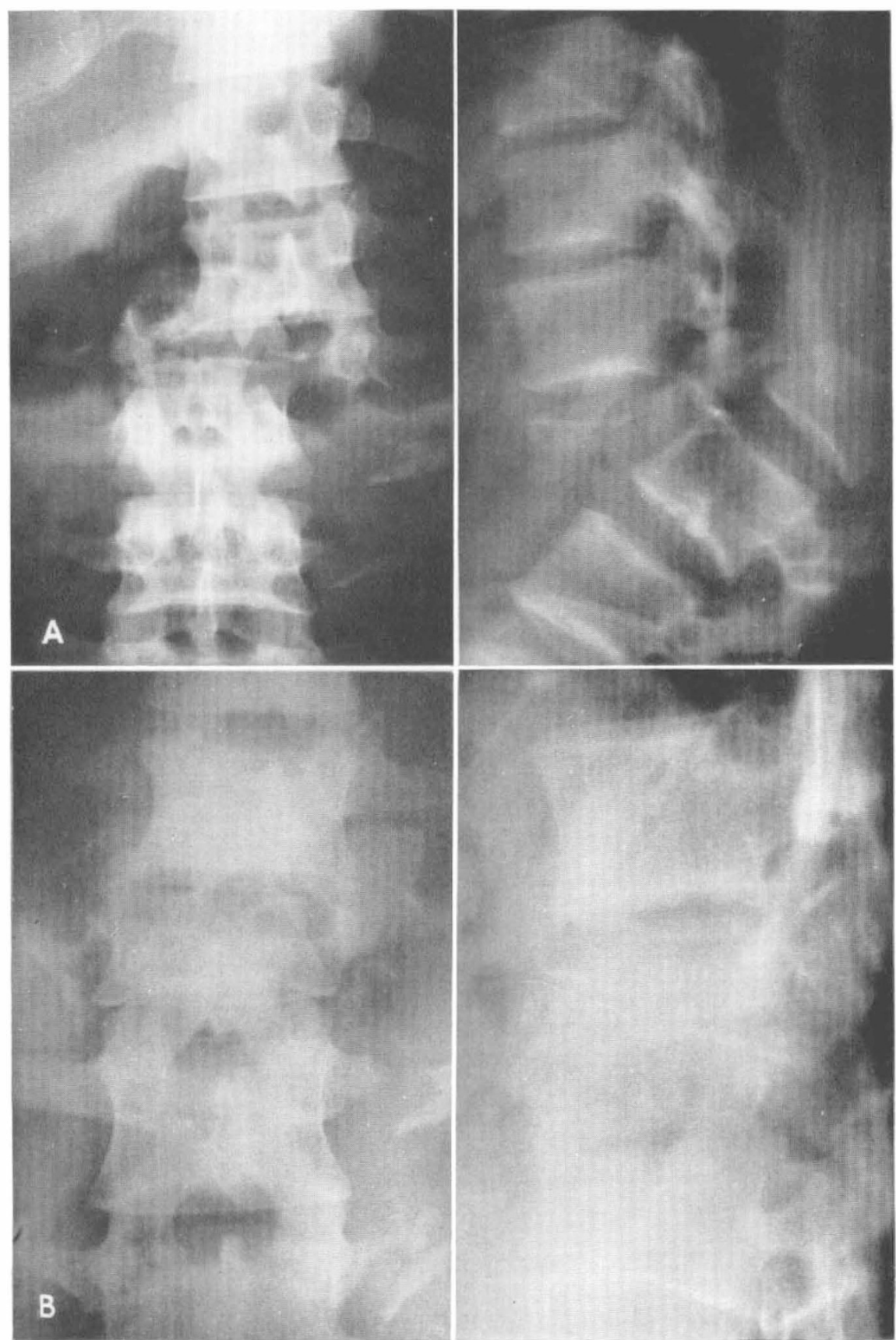

FIG. 5

(a) N. E., dislocated fracture of 2nd lumbar vertebra, roentgenogram on day of accident. (b) The same case after reduction according to L. Böhler. 
of such damage. In our patients, however, we have not noted any deterioration of the condition following this treatment.

Guttmann (I954) has shown that solely by placing pillows or rolls underneath the fracture for the purpose of hyperextension an ideal reduction or at least a clear improvement of the fracture-dislocation can be achieved. In cervical injuries he uses, in addition, skull traction by Crutchfield or Cone tongs. He considers this kind of conservative procedure less dangerous than manual reduction or reduction by ventral suspension, as it is achieved gradually and, in particular, without the use of force. In his opinion, further destruction of tissue is thus avoided, while the capacity for recovery of the spinal cord is greatly increased. Guttmann (I96I) does not consider it a disadvantage to extend the time needed for reduction by, possibly, several days, since radiography, as we pointed out above, does not produce any evidence as to the condition of the spinal cord. We, too, have been applying this method for some time and are now using it exclusively. In the cervical and dorsal spine we achieve hyperextension by placing pillows and rolls underneath the fracture. For treatment of the thoraco-lumbar junction, the Kifa tray (fig. 6),

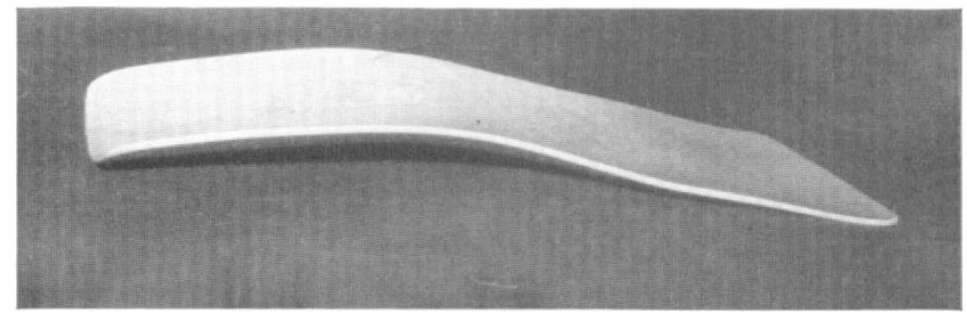

FIG. 6

'Kifa tray', manufactured by Messrs. Kifa, Stockholm, Sweden.

which is padded as needed, has for years proved highly satisfactory. Our own experience with this method of treatment is not large enough as yet to allow final conclusion. It is certain, however, that fractures which at first seem entirely unsuited for such a procedure, sometimes show an ideal position immediately after having been placed on appropriate pillows (figs. $7 a$ and $b$ ). Often, however, an improvement of the position is seen after 24 hours only, when complete relaxation of the muscles has taken place. In one case where this method was used, we did not succeed in reducing the dislocation completely. An attempt at reduction by longitudinal traction, made 24 hours later, had to be abandoned without result (figs. $8 a$ and $b$ ).

In cervical spine injuries, we have given preference to the Glisson sling as against the Crutchfield tongs and similar devices.

Apart from the question of the best method of reduction, a further subject of discussion is the problem of the most favourable method of immobilisation. Here it has to be said that every procedure known has produced a considerable number of unsatisfactory results. Immobilisation by plaster fixation, which would seem the obvious method of choice, is impracticable on account of the danger of pressure sores connected therewith. Unfortunately, this fact has, so far, not found full recognition. Furthermore, operative methods have been widely applied and are still in use. Immediate fixation of the fractured vertebra with chips and frames of bone, metal plates and wire slings is by no means safer than mere recumbency. 


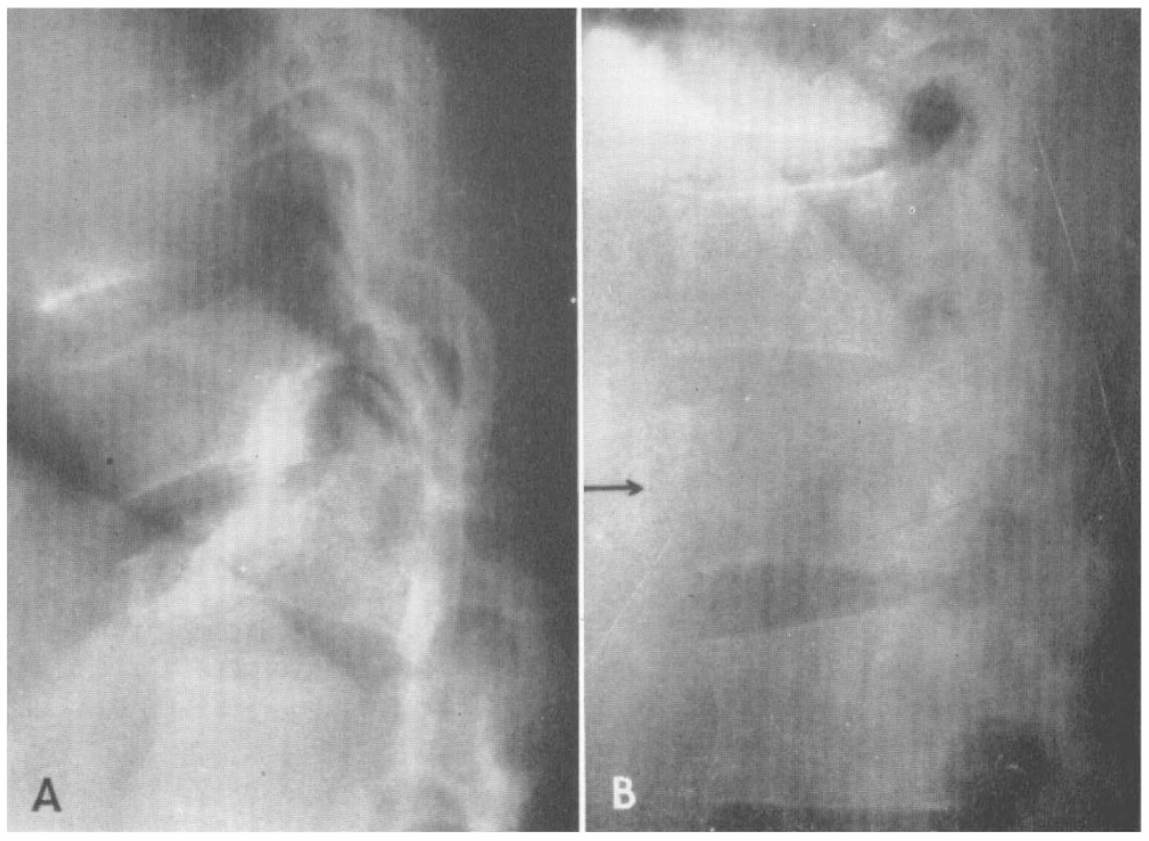

FIG. 7

(a) K. H., dislocated fracture of Ist lumbar vertebra, roentgenogram on day of accident. (b) The same case immediately after having been placed on 'Kifa tray'.
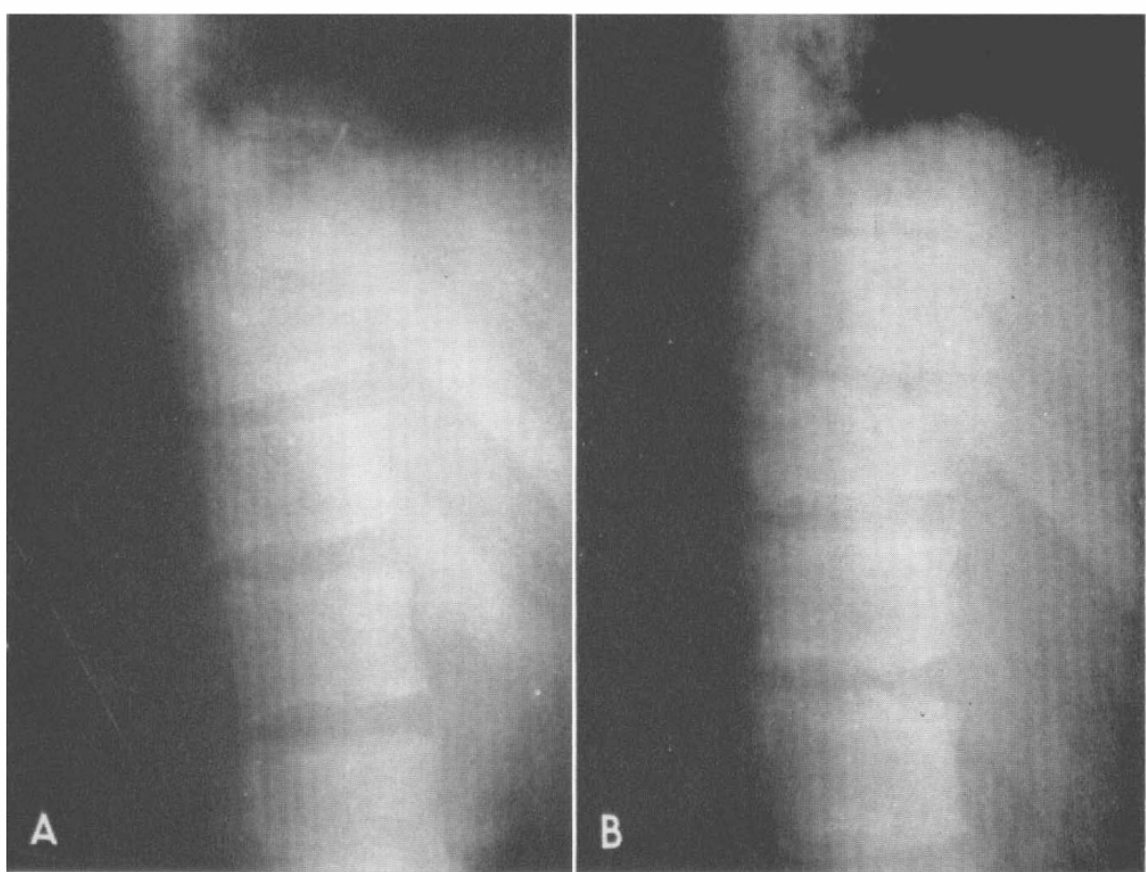

Fig. 8

(a) M. B., fracture of I2th dorsal vertebra after having been placed on 'Kifa tray'. No reduction. (b) The same case after longitudinal traction; dislocation could not be reduced either. 
Apart from the danger of infection and of necrosis of parts of bone (spinous processes), there is also the danger of the organism trying to eliminate the inserted foreign bodies. Gibbus has developed again and again, in spite of the inserted foreign bodies. Moreover, they exert pressure on the skin, thereby favouring the development of pressure sores. Therefore, irrespective of the method of reduction we have chosen, we place the patient in prone position with hyperextension of the spinal column. The ensuing results are controlled by repeated radiographs. The results depend, to a large extent, on the number and the skill of the nursing staff and on the understanding and will-power of the patient. Hyperextension must also be maintained with appropriate support, when the patient is in the lateral position, and change of position must be managed with extreme care. The more the pain in the fracture area decreases the greater the risk of a new deformity of the fractured vertebra. Quite often, it cannot be avoided altogether-a fact also known in plaster fixation. Frequently a new wedge-shaped deformity is observed, while redislocation, fortunately, is a rarity (fig. 9).

Care of the Skin. In the course of the years, we have placed our patients on air rings, water pillows, foam rubber, and Moltopren mattresses, mattresses with

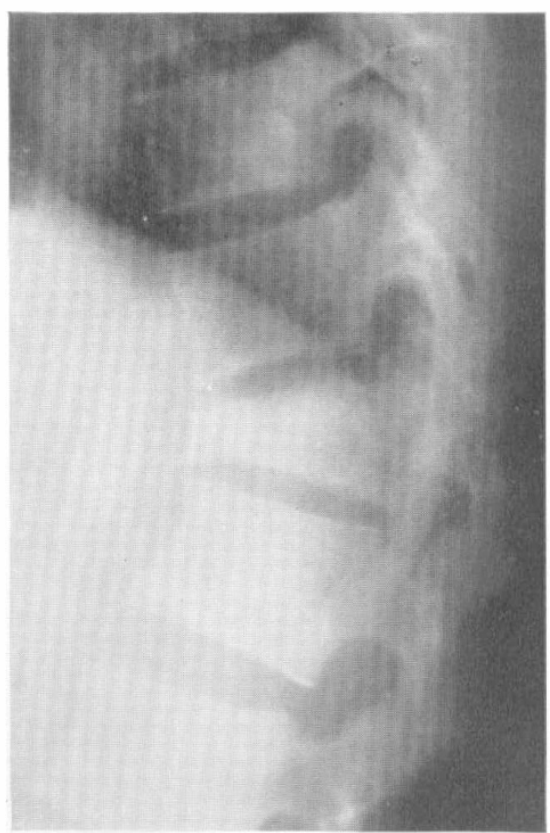

FIG. 9

The same case as in Figs. $7 a$ and $b$, six weeks later the wedge-shaped deformity began to show in which the fracture healed. instances be avoided, but pressure sores in the proper sense are definitely an exception. As a supporting measure, we take care that the value of haemoglobin changing pressure and normal ones. The turning beds (Stryker Frame) have not proved to be of great advantage. Foam rubber mattresses and those with changing pressure are still being used in our hospital. Freshly injured patients are placed on several foam rubber squares (sorbo packs) which leave space for prominent bones. We had them made after the sorbo packs developed by Guttmann (fig. I0). Pressure on the skin varies. Air rings and water pillows are completely unsuitable. However, more important than the kind of bedding the patient is placed on, is the strict turning of the injured at regular intervals of one hour and later of two to three hours. This treatment alone is sufficient to avoid pressure sores. In order to meet the danger of dislocating the fractured vertebrae when turning the patient, we need four orderlies for the freshly injured cervical spine patient and three for patients with injuries in other parts of the spinal column.

At the slightest reddening of the skin, this area of the body is kept completely off pressure until the reddening decreases. It is treated with vasodilator ointment. Blisters are removed and on their site damp bandages are applied. Skin damage cannot in all 


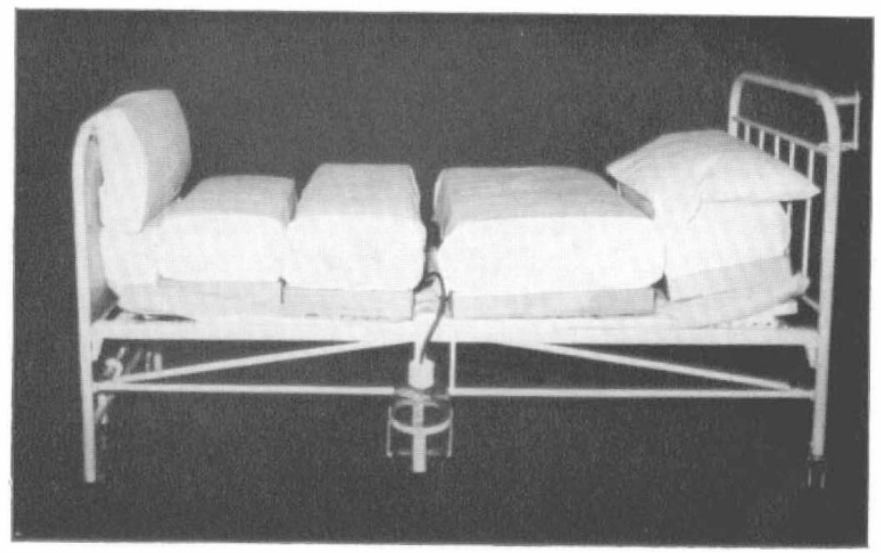

FIG. IO

Bed with 'Sorbo packs' and bottle for collecting urine.

is at least 90 per cent., and by means of an appropriate diet and by infusions of amino acids and the like we try to prevent loss of protein.

Management of the Bladder. In the presence of paralysis of the bladder we do not interfere for at least 24 hours. Only then do we catheterise according to the rules of the 'non-touch' technique developed by Guttmann (I953). Owing to shortage of personnel, however, his demand that this treatment be carried out by doctors only cannot be materialised at our hospital. We have, therefore, appropriately instructed, qualified orderlies. At first, we catheterise every 12 hours. If the initial retention of urine ceases and the bladder contains more than $500 \mathrm{ml}$., we proceed to drain the bladder three times within 24 hours, until the bladder develops a rhythm of its own. On account of certain infection and possible development of a contracted bladder, we do not advocate suprapubic cystostomy. For similar reasons we reject an indwelling catheter which, if closed, causes the danger of reflux. Orchitis or urethral fistulae are complications not seldom arising from treatment with indwelling catheters. We employ this method only temporarily in cases of urinary infection accompanied by high temperatures.

We no longer resort to tidal drainage in the early stages of treatment, but use it only temporarily for continuous washouts of infected bladders. As a measure of prophylaxis we prescribe urinary antiseptics and acidifying agents. If repeated urinary examination produces evidence of infection, we use sulphonamides together with antibiotics in accordance with resistance tests' findings. Although we have not been able as yet in the treatment of bladder infections to achieve results as satisfactory as those described by Guttmann, a definite decrease of the dangerous diseases of bladder and kidney can be reported since the measures outlined above have been strictly carried out.

Care of the Bowels. In the early stage, we produce bowel action, preferably every day, by administering enemas, prostigmine and laxatives. Digital evacuation of the rectum is avoided as long as possible. 
Relief of Pain. By administering corticosteroids, vasodilator drugs and a high dosage of vitamins we try to encourage the regenerative capacity of those parts of the spinal cord that are not completely destroyed. For the relief of pain we use mixtures of novalgin and neurotropic drugs, and in the first few days and weeks we give the patient sedatives. Opiates and their derivatives are not used at all.

Physiotherapy. We immediately start a thorough programme of physical exercises supervised by experienced physiotherapists. Paralysed and non-paralysed parts of the body are equally treated. Massage has been abandoned almost completely in favour of passive movements. At the first signs of spasticity, routine electrotherapy is discontinued. Apart from being submitted to breathing exercises, the cervical spine patient is forced to cough thoroughly several times a day. Physiotherapy constitutes an invaluable factor in rehabilitation. Keeping the paralysed limbs in a suitable functional position is an indispensable part of nursing.

Occupational Therapy. Correlated with the above is occupational therapy. Its object is to restore confidence in the remaining capacity for work and, by means of functional occupation, to support the restoration of partly immobilised mechanisms and the development of compensatory mechanisms. It thus prepares the patient for later vocational therapy. Physiotherapist and occupational therapist co-ordinate their plans of procedure very closely.

This treatment, which is essentially based on the methods worked out by Guttmann, has proved very effective. But it does call for a large staff and much space, and the larger the Centre the more economical the management of these patients. Despite many efforts to bring these consideration to the attention of the authorities concerned, they have not always been met with the necessary understanding.

\section{REFERENCES}

BöHLER, L. (I95I). Technik derKnochenbruchbehandlung, I2, I3. Aufl. Wien: Maudrich. BÜRKLE DE LA CAMP, H. (1959). Berufsgenossensch. 7, 291.

BÜRKLE DE la CAMP, H. (I959). Z Zbl. Chir. 84, I034.

BÜRKLE DE LA CAMP, H. (I96I). Hefte Z. Unfallheilk. 66, I I2.

BÜRKLE DE LA CAMP, H. (I96I). Langenbecks Arch. klin. Chir. 298, 203.

GutTMAnN, L. (1953). In History of the Second World War, United Kingdom Medical Series. Surgery, p. 422, ed. Cope, $Z$. London: Her Majesty's Stationery Office.

Guttmann, L. (1954). Proc. R. Soc. Med. 47, I 103.

Guttmann, L. (1956). Dtsch. Z. Nervenheilk. 175, 173.

Guttmann, L. (196I). Langenbecks Arch. klin. Chir. 298, I84.

MEINECKE, F.-W. (1960). Med. Welt. (Berl.), 23, I28I.

MeINECKE, F.-W. (I963). Mschr.Unfallheilk. 66, 394.

TönNIs, D. (1963). Beitr. Neurochir. 5.

ZÜLCH, K. J. (1954). Dtsch.Z. Nervenheilk. I72, 8I. 